\title{
Allocation and Use of Section 5310 Funds in Urban and Rural America
}

Tom Seekins, Alexandra Enders, Alison Pepper, and Stephen Sticka, Research and Training Center on Disability in Rural Communities of the Rural Institute, University of Montana

\begin{abstract}
Public transportation is a critical part of a community's infrastructure for people with disabilities. Section 5310 of the Transportation Equity Act is a Federal program of capital assistance to address the mobility needs of the elderly and persons with disabilities. We identified 4,835 Section 5310 recipients in 49 states and the District of Columbia, and randomly selected 750 for a mail survey. The majority were organizations serving senior citizens or individuals with developmental disabilities. Only one was a tribal entity. Overall, Sec. 5310 vehicles made up 32 percent of the respondents' fleets and 75 percent were lift equipped. More Sec. 5310 resources went to those organizations serving a mix of urbanized and rural areas than went to organizations serving rural-only areas. Ten percent of the respondents reported being faith-based organizations; more of these were in urban than rural areas. Almost half of the respondents participated in some form of cooperative system but less than 5 percent participated in a consolidated system. This study provides a baseline against which to measure changes following the implementation of the Transportation Act of 2005.
\end{abstract}




\section{Introduction}

Approximately 47 million Americans over 15 years of age report having a disability (U.S. Census 2000). Applying transportation classifications of urbanized and nonurbanized populations, approximately 31 million (67\%) live in urbanized areas of 50,000 or more inhabitants and 16 million (33\%) live in nonurbanized (i.e., rural) areas. For disabled individuals, the lack of transportation is consistently reported as one of their major challenges (Arcury et al. 2005; Arnold et al. 1997; Jackson et al. 1992; Johnson and Shaw 2001; Kidder 1989; National Council on Disability 2005; Nosek et al. 1992; Tonsing-Gonzales 1989).

The lack of transportation is experienced differently by urban and rural residents (Rucker 1994). For example, the Community Transportation Association of America (CTAA 2001) reports that rural public transit operates in only about half of rural counties nationwide. Similarly, the CTAA (1995) reports that a carless urban household can expect to receive about 933 public transportation trips per year compared to 25 trips per year for rural carless households. Despite the benefits of more transportation options, people with disabilities living in urban areas also experience significant problems with transportation (Johnson and Shaw 2001; National Council on Disability 2005). This is likely due to problems in using and dissatisfaction with existing urban transportation services (e.g., Denson 2000), as opposed to problems created by the absence of services.

Section 5310 of the Federal Transit Act (49 USC 5310) authorizes a program of transit capital assistance to address mobility needs of the elderly and persons with disabilities. Established in 1979, this program helps local organizations acquire vehicles to provide transportation services for these individuals when other public transportation is unavailable or insufficient. While this program is designed primarily to fund the purchase of vehicles, Federal law allows funds to be used for "purchase of service arrangements," such as voucher programs (e.g., Bernier and Seekins 1999).

Sec. 5310 transportation funds are allocated to states, which in turn distribute them to eligible local applicants (e.g., Federal Transit Administration 1998). Typically, local programs provide a 20 percent match and all operational costs. These funds are often used by local nonprofit organizations to provide transportation for their clientele to and from service programs. For example, a community nonprofit corporation serving adults with intellectual or developmental disabilities might use a vehicle acquired through a Sec. 5310 program to transport clients from a group home they operate to a sheltered workshop at which the clients work. 
Similarly, a local senior center may use a lift-equipped vehicle acquired through a Sec.5310 program to transport elderly community residents from their homes to the center for activities.

This "agency-driven" model provides some transportation in both urbanized and rural areas but it does not directly address the general mobility needs of all elders and persons with disabilities in a community. Further, while there is recent evidence of increasing coordination, critics have long suggested that vehicles operated under this model may be underused and nonclients may be excluded from riding in the vehicles, even if their destinations overlap (e.g., Sundeen et al. 2005; U.S. Department of Transportation 1980).

Several reports discuss transportation issues for elderly individuals and people with disabilities (Government Accountability Office 2004) but surprisingly little quantitative research has been published about transportation for people with disabilities (e.g., Rucker 1994). Burkhardt et al. (2004) identified three levels of cooperative systems, including coordinated systems, brokerages, and consolidated systems. Kidder (1989) showed that a cooperative model in which local human service agencies consolidated operations could greatly expand transportation within a community. Unfortunately, little is known about the extent to which such cooperative models have been implemented or their effectiveness. Moreover, Federal regulation has not required recipients of Sec. 5310 funds to cooperate with each other (Burkhardt et al. 2004; Government Accountability Office 2003). ${ }^{1}$ Rural disability service providers, advocates, and transportation planners need data on the actual distribution and use of Sec. 5310 funds in urbanized and rural areas (e.g., APRIL 2001) so they can effectively organize resources to maximize the availability and use of transportation. Further, there is a need to establish a baseline of such information against which the effects of new regulations and provisions of future transit acts may be evaluated.

The goal of this study was to assess the distribution and use of Sec. 5310 funds at the local level, specifically focusing on comparisons between urban and rural areas. We hypothesized that Sec. 5310 funds are inequitably distributed between programs located in urbanized and rural areas. We also hypothesized that fewer than 25 percent of Sec. 5310 recipients would report participating in any type of cooperative system and that less than 60 percent of vehicles purchased with Sec. 5310 funds would be accessible to persons with mobility impairments.

Further, we expected to find that those who do participate in cooperative systems would report greater efficiency and effectiveness as measured by the number 
of riders and trips provided. Given the limited information about the Sec. 5310 program, we also sought to describe the characteristics of these transportation providers and how they used these resources.

\section{Method}

\section{Sample Population}

Respondents to the survey were staff of local service programs receiving Sec. 5310 assistance from their state. We contacted state Sec. 5310 coordinators by phone and email to secure lists of local recipients of Sec. 5310 assistance. We followed CTAA's definition of the active network of Sec. 5310 recipients as any organization operating a vehicle acquired with Sec. 5310 assistance that is still within its anticipated useful life (e.g., CTAA 2006). Forty-seven states and the District of Columbia provided comprehensive lists of local recipients. Texas and Florida administered their programs through regional offices and those regional offices provided 32 lists of local recipients. North Carolina transferred all of its Sec. 5310 funds into the operation of its Sec. 5311 rural transit program, so it was excluded from this study. Overall, we identified 4,835 recipients of Sec. 5310 assistance in the 49 states and the District of Columbia. Our original data analysis plan suggested that the most demanding analysis would involve F-tests to explore differences across five regional groups. A power analysis (Fetterman 1998) suggested that a sample size of 375 would be needed for an expected small-to-medium effect size of .18 with an Alpha of .05 and power of 8 . Anticipating a 60 percent return rate using Dillman's (2000) survey procedures, we selected a pool of 625 respondents to achieve the needed sample of 375 . To increase likely responses and limit followup, we increased that initial sample to 750 respondents selected at random from the list of 4,835 .

\section{Survey Instrument and Procedures}

We took several steps to develop the survey instrument. First, we reviewed several states' Sec. 5310 transportation policies and procedures. Next, we reviewed current literature on transportation programs to identify relevant issues. We developed a list of hypotheses about the Sec. 5310 program (e.g., funds would be disproportionately allocated to urban areas on a per capita basis, larger programs would be more likely to have accessible vehicles, rural respondents would be less likely to report participating in a cooperative system, etc.) and developed a "hypothetical report" of findings. This hypothetical report clarified the issues we 
wanted to address. We drafted a survey to reflect the hypotheses and the hypothetical report. We then compared the content of the survey instrument to the hypothetical report to ensure that our questions addressed those issues. We asked several community transportation experts to review and comment on the survey draft. Researchers then conducted a read-aloud procedure with a potential survey respondent and edited survey items the respondent found confusing. Experts again reviewed the final draft and we incorporated their suggested changes.

The completed questionnaire contained 24 items, including:

- Seven questions about the characteristics of the organization and its service area,

- Four questions addressing the status of transportation services in the respondent's community,

- Two questions about Sec. 5310 resources received,

- Three questions about the characteristics of the organization's vehicle fleet,

- Two questions about the amount of transportation services provided,

- Five questions about various aspects of local coordination, and

- One open-ended question to allow for comments.

For consistency, we asked respondents to provide their answers using data from FFY 2002, the last official reporting period.

Local coordination is a particularly complex issue. The term coordination has been used to reflect a range of practices (e.g., Burkhardt et al. 2004). In an attempt to clarify the concept, we organized three major strategies under the concept of cooperative systems:

1. Coordinated systems in which independent agencies coordinate service areas and target groups, or pool purchases

2. Brokerages in which agencies coordinate schedules or "broker" rides across agency clientele

3. Consolidated systems in which several agencies pool all of their transit resources into a separate transportation agency that serves the entire community

We followed survey procedures specified by Dillman (2000). A postcard announcing the survey was sent to selected respondents. Two weeks later, we mailed a 
cover letter, survey, and self-addressed return envelope to those respondents. After two weeks, we sent a reminder postcard encouraging completion and return of the survey. Two weeks later, we sent a second survey packet to all those who had not yet responded.

\section{Data Analysis Methods}

We used SPSS 11.5 to examine the data. Standard descriptive statistics were calculated to describe the demographics and general-use patterns of Sec. 5310 recipients. We conducted correlation analyses to examine relationships between variables and examined the data for differences across groups using ANOVA. As the central hypothesis states an expected direction in resource allocation, we used a one-tailed t-test of proportions to examine the direction of differences.

\section{Results}

A total of $305(n=305)$ local recipients of Sec. 5310 assistance from 49 states and the District of Columbia responded to our survey. Another 30 surveys were returned by the post office as undeliverable, yielding an effective response rate of 45 percent.

We created three geographic groups for analysis:

1. An urban-only services group $(n=60)$ composed of those operating solely in urbanized areas of 50,000 or more inhabitants

2. A rural-only services group $(n=127)$ composed of respondents operating solely in small towns and rural areas with fewer than 50,000 inhabitants

3. A mixed group serving both urbanized and rural areas $(n=74)$

Table 1 shows the number and proportion of respondents serving four distinct geographic areas. Forty-nine percent of recipients operated exclusively in small towns or rural areas outside of urbanized areas.

Of the respondents, 204 (79\%) reported being a private not-for- profit agency, 48 (19\%) reported being a local government entity, 7 (3\%) reported being a state agency, and only one reported being a tribal organization. No respondent reported being a private for-profit agency or a tribal government unit. Table 2 depicts the types of programs that recipients operated across urban and rural areas. Interestingly, respondents who were exclusively transit providers in urban areas accounted for only 6.7 percent $(n=4)$ of recipients of Sec. 5310 assistance, 


\section{Table 1. Geographic Areas Served by Respondents}

\begin{tabular}{lcc}
$\begin{array}{l}\text { Geographic Areas } \\
\text { Served }\end{array}$ & $\begin{array}{c}\text { Number } \\
\text { Reporting }\end{array}$ & $\begin{array}{c}\text { Percent } \\
\text { Reporting }\end{array}$ \\
\hline $\begin{array}{l}\text { Urbanized Area } \\
\text { Over 200,000 } \\
\text { People }\end{array}$ & 37 & $14 \%$ \\
Urbanized Area of & 23 & \\
$\begin{array}{l}50,000-200,000 \\
\text { People }\end{array}$ & & $9 \%$ \\
$\begin{array}{l}\text { Small Towns or } \\
\text { Rural Areas Outside } \\
\text { of Urbanized Area }\end{array}$ & 127 & $49 \%$ \\
$\begin{array}{l}\text { Both Urbanized and } \\
\text { Rural Areas }\end{array}$ & 74 & \\
\end{tabular}

Table 2. Program Type by Urban, Mixed, and Rural Service Groups

\begin{tabular}{|l|c|c|c|c|c|c|c|c|}
\hline Program Type & All & Percent & Urban & Percent & $\begin{array}{l}\text { Mixed, } \\
\text { Urban, } \\
\text { Rural }\end{array}$ & Percent & $\begin{array}{l}\text { Rural } \\
\text { Only }\end{array}$ & Percent \\
\hline Senior Services Agency & 92 & $35.0 \%$ & 21 & $35.0 \%$ & 20 & $27.0 \%$ & 50 & $39.4 \%$ \\
\hline $\begin{array}{l}\text { Developmental } \\
\text { Disabilities Agency }\end{array}$ & 65 & $24.7 \%$ & 19 & $31.7 \%$ & 15 & $20.3 \%$ & 31 & $24.4 \%$ \\
\hline $\begin{array}{l}\text { Social or Community } \\
\text { Service Provider }\end{array}$ & 30 & $11.4 \%$ & 10 & $16.7 \%$ & 9 & $12.2 \%$ & 10 & $7.9 \%$ \\
\hline $\begin{array}{l}\text { Exclusively Rural Transit } \\
\text { Provider }\end{array}$ & 24 & $9.1 \%$ & 0 & $0.0 \%$ & 4 & $5.4 \%$ & 20 & $15.7 \%$ \\
\hline $\begin{array}{l}\text { Exclusively Urban } \\
\text { Transit Provider }\end{array}$ & 3 & $1.1 \%$ & 3 & $5.0 \%$ & 0 & $0.0 \%$ & 0 & $0.0 \%$ \\
\hline $\begin{array}{l}\text { Other Disability Services } \\
\text { Organization }\end{array}$ & 14 & $5.3 \%$ & 3 & $5.0 \%$ & 5 & $6.8 \%$ & 6 & $4.7 \%$ \\
\hline Other & 18 & $6.8 \%$ & 3 & $5.0 \%$ & 8 & $10.8 \%$ & 7 & $5.5 \%$ \\
\hline $\begin{array}{l}\text { Exclusively Transit } \\
\text { Agency Serving Urban } \\
\text { and Rural Areas }\end{array}$ & 17 & $6.5 \%$ & 1 & $1.7 \%$ & 13 & $17.6 \%$ & 3 & $2.4 \%$ \\
\hline Total & 263 & $100.0 \%$ & 60 & $100.0 \%$ & 74 & $100.0 \%$ & 127 & $100.0 \%$ \\
\hline
\end{tabular}


while exclusive transit agencies accounted for 23 percent $(n=17)$ and 18 percent $(\mathrm{n}=23)$ of mixed and rural-only recipients.

Since transportation is only one part of most Sec. 5310 providers' program activities, we asked respondents to report both transportation and total program budgets. Respondents' FFY 2002 transportation budgets averaged $\$ 505,987$ with a median of $\$ 108,000$. Respondents' overall budgets averaged $\$ 4,853,238$ with a median of $\$ 1,277,637$. There were no statistically significant differences in agency budgets among the three geographic groups. The amount of Sec. 5310 funding received by the mixed group $(m=\$ 45,228)$ was greater than the rural-only group $(m=\$ 26,413 ; p=.018)$. The urban-only service group $(m=\$ 42,710)$ approached statistical difference with the rural only group $(p=.083)$.

Table 3 presents the total number of vehicles reported by survey respondents, the number acquired with Sec. 5310 assistance, and the proportion of vehicles that are lift equipped. Overall, Sec. 5310 vehicles made up 32 percent of all fleet vehicles. Nearly half (47\%) of all vehicles were lift equipped but 75 percent of vehicles acquired through Sec. 5310 were lift equipped. As the number of vehicles in a fleet increased, the number of vehicles purchased with Sec. 5310 assistance increased $(r=.58, p=.01)$, the number of Sec. 5310 vehicles equipped with a lift increased $(r=.79, p=.01)$, and the number of vehicles in the general fleet equipped with a lift increased $(r=.48, p=.01)$. There were also positive correlations between the total number of Sec. 5310 vehicles in a fleet and the number of Sec. 5310 vehicles

\section{Table 3. Total and Accessible Vehicles by General Fleet and Sec. $\mathbf{5 3 1 0}$ Across Geographic Groups of Respondents}

\begin{tabular}{|l|c|c|c|c|c|c|c|c|c|}
\hline & Total & Average & Median & $\begin{array}{c}\text { Urban } \\
\text { Only }\end{array}$ & $\begin{array}{c}\text { Percent } \\
\text { of Total }\end{array}$ & $\begin{array}{c}\text { Mixed, } \\
\text { Urban, } \\
\text { Rural }\end{array}$ & $\begin{array}{c}\text { Percent } \\
\text { of Total }\end{array}$ & $\begin{array}{c}\text { Rural } \\
\text { Only }\end{array}$ & $\begin{array}{c}\text { Percent } \\
\text { of Total }\end{array}$ \\
\hline $\begin{array}{l}\text { Total Agency } \\
\text { Vehicles }\end{array}$ & 3,537 & 13.5 & 6 & 862 & $24 \%$ & 1,258 & $36 \%$ & 1,406 & $40 \%$ \\
\hline 5310 Vehicles & $\begin{array}{c}1,150 \\
(32 \%)\end{array}$ & 4.4 & 3 & $\begin{array}{c}206 \\
(24 \%)\end{array}$ & $18 \%$ & $\begin{array}{c}467 \\
(37 \%)\end{array}$ & $41 \%$ & $\begin{array}{c}473 \\
(34 \%)\end{array}$ & $41 \%$ \\
\hline $\begin{array}{l}\text { Accessible } \\
\text { Vehicles in } \\
\text { General Fleet }\end{array}$ & $\begin{array}{c}1,656 \\
(47 \%)\end{array}$ & 6.3 & 3 & $\begin{array}{c}425 \\
(49 \%)\end{array}$ & $26 \%$ & $\begin{array}{c}674 \\
(54 \%)\end{array}$ & $41 \%$ & $\begin{array}{c}549 \\
(39 \%)\end{array}$ & $33 \%$ \\
\hline $\begin{array}{l}5310 \text { Accessible } \\
\text { Vehicles }\end{array}$ & $\begin{array}{c}867 \\
(75 \%)\end{array}$ & 3.3 & 2 & $\begin{array}{c}155 \\
(75 \%)\end{array}$ & $18 \%$ & $\begin{array}{c}337 \\
(72 \%)\end{array}$ & $39 \%$ & $\begin{array}{c}370 \\
(78 \%)\end{array}$ & $43 \%$ \\
\hline
\end{tabular}


that were lift equipped $(r=.50, p=.01)$, and the overall number of lift-equipped vehicles in the fleet $(r=.70, p=.01)$.

Moreover, analysis showed significant differences on these measures across geographic groups. Specifically, the mixed group had more Sec. 5310 vehicles per provider $(m=6.31)$ than either the urban-only $(m=3.43 ; p=.005)$ or rural-only groups ( $m=3.72 ; p=.002$ ). The mixed group also reported a significantly greater proportion of their Sec. 5310 vehicles were lift equipped $(m=4.55)$ than either the urban-only $(\mathrm{m}=2.67 ; \mathrm{p}=.008)$ or rural-only $(\mathrm{m}=2.94 ; \mathrm{p}=.006)$ groups. Finally, the mixed group averaged more lift-equipped vehicles in its fleet $(m=9.23)$ than those in the rural-only group $(m=4.36 ; p=.008)$.

Survey respondents reported providing 5,897,058 one-way passenger trips in FFY 2002; an average of 25,978 (s.d. $=94,320$ ) per agency but a median of 5,696 trips. The rural-only group reported providing an average of 13,000 one-way trips. The urban-only group provided an average of 31,158 trips. The mixed group averaged 44,021 trips. There were no statistically significant differences in the number of one-way trips provided between these groups. ${ }^{2}$

While there were no statistically significant differences in the total agency budgets among the three geographic groups, the mixed group received significantly more Sec. 5310 funding than the rural-only group. Further, organizations operating larger fleets were more likely to acquire accessible vehicles, as were agencies that operated more Sec. 5310 vehicles.

Table 4 presents the number of counties served, the average number of riders per county, the average number of mobility-impaired riders per county across the three geographic groups, and the number of other transportation providers in these counties. The number of other transit providers is important when considering the potential for developing cooperative transit arrangements. A oneway ANOVA showed that there were significant differences between the three geographic groups in the number of counties served $F(2,258)=3.80, p=.02$, and the number of other public or private transit providers $F(2,258)=5.22, p=.006$. Tukey's post-hoc analyses showed that urban-only providers $(M=1.10, S D=.75)$ serve significantly fewer counties than those providers who serve mixed areas ( $M$ $=1.70, \mathrm{SD}=1.34$; mean difference $=-.60, \mathrm{p}=.018$ ). Further, rural-only providers $(M=3.35, S D=4.85)$ estimated significantly fewer other public or private transit providers than providers who serve mixed areas $(M=12.93, S D=37.02$; mean difference $=-9.58, p=.005$ ). There were no statistically significant differences among 
the number of riders per county or the number of mobility-impaired riders served per county.

\section{Table 4. Average Number of Counties Served, Riders per County, and Other Providers with Whom to Cooperate Across the Three Geographic Groups}

\begin{tabular}{|l|c|c|c|c|}
\hline & $\begin{array}{c}\text { All } \\
\text { Respondents }\end{array}$ & $\begin{array}{c}\text { Urban } \\
\text { Only }\end{array}$ & $\begin{array}{c}\text { Mixed Urban } \\
\text { and Rural }\end{array}$ & $\begin{array}{c}\text { Rural } \\
\text { Only }\end{array}$ \\
\hline $\begin{array}{l}\text { Average Counties } \\
\text { Served }\end{array}$ & 1.5 & 1.1 & 1.7 & 1.5 \\
\hline $\begin{array}{l}\text { Average Riders } \\
\text { Served Annually }\end{array}$ & 34,630 & 110,419 & 8,353 & 14,557 \\
\hline $\begin{array}{l}\text { Average Number of } \\
\text { Riders with Mobility } \\
\text { Impairments }\end{array}$ & 972 & 451 & 1,639 & 843 \\
\hline $\begin{array}{l}\text { Average Number of } \\
\text { Other Transportation } \\
\text { Providers }\end{array}$ & 7.4 & 9.2 & 12.9 & 3.35 \\
\hline
\end{tabular}

Twenty-six (10\%) respondents reported being a faith-based organization. Of these faith-based organizations, significantly more are located in the urban-only services group $(n=12 ; 20 \%)$ than in the rural-only $(n=6$ or $5 \%)$ or mixed groups $(n=7$ or $10 \%$ mean difference $=.15, p=.003$ ).

Table 5 shows the number of respondents reporting participating or not participating in cooperative systems across the geographic groups. Forty-six percent of respondents participated in some form of cooperative transportation system but only 14 percent participated in a brokerage system and only 5 percent participated in a consolidated system. There were no statistically significant differences in the likelihood of participating in a cooperative system across geographic groups. Nine faith-based providers (35\%) reported participating in some form of cooperative system.

Of those not participating in any form of cooperative system, 16 (12\%) reported that there was no need and $28(20 \%)$ reported that there were no other providers with which to cooperate. Twenty-four (86\%) of the 28 who reported that there were no other providers with which to cooperate were in the rural-only services group. Since several rural providers reported that there were no other providers 
with which to cooperate, we also conducted this analysis after removing those respondents. Still, no statistically significant differences emerged. It must be noted, however, that reports that there are no other providers in an area may not be highly reliable.

Table 5. Cooperative Systems by Rural, Mixed, and Urban Provider Groups

\begin{tabular}{|l|c|c|c|c|}
\hline $\begin{array}{l}\text { Cooperative } \\
\text { Systems }\end{array}$ & $\begin{array}{c}\text { All } \\
\text { Respondents } \\
\text { Number and } \\
\text { Percent }\end{array}$ & $\begin{array}{c}\text { Urban } \\
\text { Services } \\
\text { Group }\end{array}$ & $\begin{array}{c}\text { Mixed, } \\
\text { Urban, } \\
\text { Rural } \\
\text { Group }\end{array}$ & $\begin{array}{c}\text { Rural } \\
\text { Services } \\
\text { Group }\end{array}$ \\
\hline $\begin{array}{l}\text { Does Not } \\
\text { Participate }\end{array}$ & $138(54 \%)$ & $37(64 \%)$ & $33(45 \%)$ & $67(55 \%)$ \\
\hline $\begin{array}{l}\text { Participated in a } \\
\text { Coordinated System }\end{array}$ & $68(27 \%)$ & $11(19 \%)$ & $21(29 \%)$ & $35(29 \%)$ \\
\hline $\begin{array}{l}\text { Participates in a } \\
\text { Brokerage }\end{array}$ & $36(14 \%)$ & $7(12 \%)$ & $15(21 \%)$ & $14(12 \%)$ \\
\hline $\begin{array}{l}\text { Participates in a } \\
\text { Consolidated } \\
\text { System }\end{array}$ & $12(5 \%)$ & $3(5 \%)$ & $4(5 \%)$ & $5(4 \%)$ \\
\hline
\end{tabular}

Those agencies participating in some form of cooperative system had larger agency budgets $\mathrm{t}(104.9)=-1.945, \mathrm{p}=.054$, had larger transportation budgets $\mathrm{t}(121.5)=-2.813, \mathrm{p}=.006$, and received more Sec. 5310 funds $\mathrm{t}(151.3)=-2.965, \mathrm{p}=$ .004. In addition, those agencies participating in some type of a cooperative system provided more one-way trips $\mathrm{t}(103.9)=-2.025, \mathrm{p}=.045$. There were no statistical differences in the number of one-way trips per vehicle provided by those who participated in or did not participate in cooperative systems, however.

Table 6 presents the effort to organize and willingness to take part in a cooperative system by respondents who did not yet participate in a cooperative system. While it appears that respondents not participating in a cooperative system have made some attempts to organize such systems, very few of those attempts appeared to involve much effort. Most respondents were ambivalent about participating in a cooperative system but nearly 34 percent were willing or very willing to do so. There were no statistical differences in willingness to cooperate across the geographic groups. 


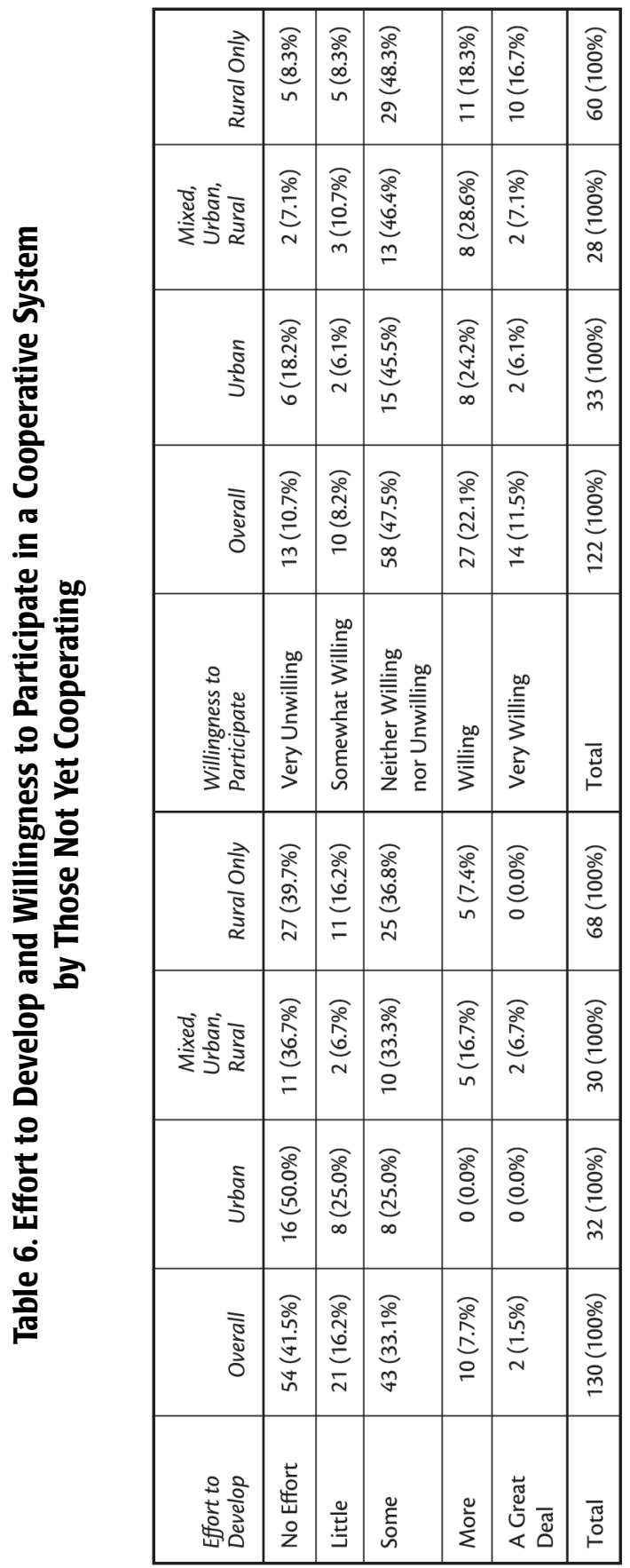


Table 7 depicts the barriers that respondents reported in trying to form a cooperative system. (Respondents were able to mark more than one barrier.) The most frequent barrier mentioned was organizational policy that required an agency to serve only its clients. This was followed by concerns over liability. Surprisingly, eight respondents reported prohibitive state policies as a barrier to cooperation.

\section{Table 7. Barriers to Cooperation Reported by Those Not Yet Cooperating}

\begin{tabular}{|l|r|r|r|r|r|r|r|r|}
\hline $\begin{array}{l}\text { Reported Barriers to } \\
\text { Cooperation }\end{array}$ & All & Percent & Urban & Percent & $\begin{array}{l}\text { Mixed, } \\
\text { Urban, } \\
\text { Rural }\end{array}$ & Percent & $\begin{array}{l}\text { Rural } \\
\text { Only }\end{array}$ & Percent \\
\hline No Need & 16 & $8.6 \%$ & 5 & $9.1 \%$ & 3 & $6.8 \%$ & 8 & $9.5 \%$ \\
\hline $\begin{array}{l}\text { No Other Local } \\
\text { Providers }\end{array}$ & 28 & $15.1 \%$ & 4 & $7.3 \%$ & 5 & $11.4 \%$ & 19 & $22.6 \%$ \\
\hline $\begin{array}{l}\text { Insurance and } \\
\text { Liability }\end{array}$ & 30 & $16.2 \%$ & 12 & $21.8 \%$ & 8 & $18.2 \%$ & 9 & $10.7 \%$ \\
\hline $\begin{array}{l}\text { Other Unwilling to } \\
\text { Cooperate }\end{array}$ & 17 & $9.2 \%$ & 4 & $7.3 \%$ & 5 & $11.4 \%$ & 8 & $9.5 \%$ \\
\hline $\begin{array}{l}\text { Organizational Policy } \\
\text { Precludes }\end{array}$ & 49 & $26.5 \%$ & 17 & $30.9 \%$ & 14 & $31.8 \%$ & 17 & $20.2 \%$ \\
\hline $\begin{array}{l}\text { Prohibitive State } \\
\text { Regulations }\end{array}$ & 8 & $4.3 \%$ & 3 & $5.5 \%$ & 2 & $4.5 \%$ & 3 & $3.6 \%$ \\
\hline Other Reasons & 37 & $20.0 \%$ & 10 & $18.2 \%$ & 7 & $15.9 \%$ & 20 & $23.8 \%$ \\
\hline Total & 185 & $100.0 \%$ & 55 & $100.0 \%$ & 44 & $100.0 \%$ & 84 & $100.0 \%$ \\
\hline
\end{tabular}

Table 8 shows the average rating of the quality of public transportation for all citizens in a service area, for people with disabilities and for elderly individuals. Quality was rated on a 5 -point scale where 0 was very poor and 4 was excellent. While there were no significant differences between or across groups, ratings fell at or below the mid-point. While there was a considerable amount of importance placed on providing accessible transportation in the areas served ( $79 \%$ rated it a 4 on the 5-point scale), at least 33 percent indicated that each of the services was inadequate. 


\section{Table 8. Average Ratings of the Quality of Public Transportation Across Geographic Groups}

\begin{tabular}{lccc} 
& All People & Elderly & $\begin{array}{c}\text { People with } \\
\text { Disabilities }\end{array}$ \\
\hline All Respondents & 1.9 & 2.0 & 1.9 \\
Urban Only & 2.0 & 1.8 & 1.7 \\
Mixed, Urban, Rural & 1.9 & 2.0 & 1.9 \\
Rural Only & 1.8 & 2.2 & 1.9
\end{tabular}

Sixteen respondents (6\%) reported using an average of $\$ 701,354$ (median of $\$ 30,000)$ for third-party contracts with other providers for purchase of services. Six respondents (2\%) reported using an average of $\$ 7,248$ to provide user-side subsidies in the form of voucher or taxi coupon models.

\section{Discussion}

This study examined the allocation and use of Sec. 5310 transportation resources nationally. We identified 4,835 local recipients of these resources in 49 states and the District of Columbia. The majority of respondents were local, not-for profit organizations that serve either senior citizens or individuals with developmental disabilities. This may mean that individuals with disabilities due to mobility impairments, chronic diseases, or psychiatric impairments are less likely to have access to this level of public transportation.

Some caution should be applied in interpreting these findings. First, our response rate was 45 percent and there may be response bias in the data. For example, some evidence suggest that larger programs and those which have received vehicles more recently responded in higher numbers than smaller organizations or ones that have not received Sec. 5310 support for some time. Second, our sample fell somewhat short of our goal of 350 responses. This means that our analysis may not have detected smaller differences between groups where they may exist. As such, some differences may exist between groups where we found none.

Rural advocates consistently report that the lack of transportation in rural areas is one of the major obstacles to community participation, especially for people with disabilities. We hypothesized that urban areas would receive more Sec. 5310 resources. In fact, respondents in the mixed group received more Sec. 5310 
resources than the rural-only group, but not more than the urban-only group. At the same time, rural-only respondents were significantly more likely to report fewer other public or private transportation providers serving their areas. Since the Sec. 5310 program was designed to provide transportation when other public transportation is unavailable, insufficient, or inappropriate, it is somewhat surprising that more of these resources do not go to rural areas. It may be that, even with the greater number of options available in urban areas, urban public transit is still insufficient or inappropriate. Perhaps, despite having fewer options, the services available in rural areas are more likely to be judged to be sufficient. It may also be that the mixed group is using its Sec. 5310 resources to fill the transportation gaps in the rural areas they serve. Alternatively, it may be that the mixed and urbanonly recipients are more aware of this source of funds, have more experienced proposal writers, or are beneficiaries of policies that limit access to Sec. 5310 resources to those who have already received them.

We hypothesized that less than 60 percent of vehicles purchased with Sec. 5310 resources would be accessible to persons with mobility impairments. While only 47 percent of the general fleet was wheelchair accessible, we found that 75 percent of Sec. 5310 vehicles were lift equipped. This is quite encouraging, given that agencies are not required to purchase accessible vehicles with Sec. 5310 resources but have the flexibility to balance the types of vehicles in their fleets to meet needs. Further, the vehicles reported in this study included all those still in service regardless of age. This level of accessibility is a high benchmark. It suggests that the dream of some advocates for a totally accessible fleet could be within reach.

Our data show that the recipients report providing an average of 25,978 (s.d. = 94,320 ) one-way trips per year and a median of 5,696 . Such data, if collected regularly, may contribute to establishing performance benchmarks that planners and administrators could use. Similar measures could be assessed on rides per vehicles and other factors.

We hypothesized that fewer than 25 percent of Sec. 5310 recipients would report participating in a cooperative system of any kind. In fact, we found that 47 percent reported participating in some form of a cooperative system but only 18 percent participated in the more sophisticated brokerage or consolidated forms of cooperative systems. Transportation providers face many challenges in trying to organize cooperative systems, including concerns about loss of service for their clients, loss of control over services and finances, increased demand on their vehicles, and the lack of any incentive to make the effort (e.g., Zeilinger 2003). One obstacle is 
the simple cost of the administrative effort required to plan and organize such a system. A policy option that may assist some communities to develop brokerage or consolidated systems would involve providing target funding for local planning and transition projects.

We expected to find that those who reported participating in a cooperative system would achieve greater efficiency and effectiveness than those who did not. Our data show that providers operate their vehicles at about the same capacity, however, regardless of the organizational arrangement. This may be a function of vehicle financing. That is, providers are not likely to add more vehicles to their fleets if their current vehicles are underused. Alternatively, any gains in effectiveness as measured by one-way rides per vehicle may come only when local agencies created consolidated services. Unfortunately, the number of respondents participating in consolidated systems was too low to conduct a meaningful analysis of that particular arrangement.

On the other hand, cooperative systems may achieve greater effectiveness (i.e., more total riders in an area) rather than greater efficiency (i.e., rides per vehicle). That is, while both cooperators and noncooperators may use their available vehicles to a similar capacity, cooperators may reach a larger proportion of the "eligible" riders in a given area. This view receives support from the finding that providers who reported participating in a cooperative system have more vehicles, a larger budget, serve more riders, and provide more one-way trips than those who do not cooperate. Further geographic analysis is needed that compares the number of riders served in an area to those eligible to determine whether this represents service to a larger proportion of the eligible population. Alternatively, cooperators may provide rides of greater distance or a higher level of service (e.g., extended hours, door-to-door versus curb-to-curb, etc.). We did not collect data on these dimensions.

While more than 60 percent of respondents who did not participate in any cooperative system reported little or no effort to create a cooperative system in their community, 33 percent reported that they were willing or very willing to participate in one. This is encouraging in light of the new Federal emphasis on promoting coordination. Overall, the most frequently reported barriers to cooperation included organizational policies and concern over liability. Still, some respondents indicated they believed that their state agency's regulations prohibited cooperation. These issues need further attention. One question, for example, is whether 
an organization with policies hindering coordination should be deemed eligible for Sec. 5310 assistance.

For rural respondents, the most frequently reported barrier to forming a cooperative system is the absence of other transportation providers in the area with whom to cooperate. This suggests that special attention should be given to using Sec. 5310 resources where there are no other public options, especially to serve those with mobility impairments.

Interestingly, providers that were exclusively transit agencies serving mixed and rural-only areas substantially outnumbered their counterparts in urban areas. Smaller communities may be more likely than urban communities to rely on established transit providers to meet the needs of elderly residents and persons with disabilities. North Carolina presents the largest example of this approach. The state reported investing all of its Sec. 5310 resources in its rural transit program. This strategy achieves at least three objectives. First, it emphasizes the need for additional resources for the rural transit program, which has been significantly underfunded compared to the urban (5307) program. Second, it integrates transportation services for people with disabilities into the mainstream transit program, an important value to disability advocates. Third, it may assist the rural transit program in acquiring accessible vehicles for its fleet. This model deserves further study and consideration, especially considering that there are urban and rural areas without any public transportation.

In conclusion, public and specialized transportation is a vibrant and constantly evolving national commitment. Both consumer expectation and technology change over time. National policies and regulations are intended to maximize the use of scarce transportation resources in meeting these changing needs. This study provides a baseline against which to measure the effects of future changes in this important program's policies and regulations.

\section{Acknowledgments}

This study was funded by a grant from the National Institute on Disability and Rehabilitation Research (H133B030501). The opinions expressed are those of the authors and do not represent those of the agency.

We wish to thank Chris Zeilinger, Catherine Ipsen, Dennis Stombaugh, Linda Gonzales, Devva Kasnitz, Josh Kinkdrick, Nancy Arnold, Bryna Helfer, Sue Masselink, 
and Lorna Wilson for their helpful comments and advice. We are particularly appreciative to Mr. Zeilinger of the Community Transportation Association of America for his help in developing the survey content. We are also grateful to Dave Spacek of the Illinois Department of Transportation and Janet Weaver of the Idaho Transportation Department for their thoughtful review of an early version of this manuscript. We are especially indebted to Mr. Spacek for his insight about establishing performance benchmarks that planners and administrators could use if data on one-way trips were collected regularly. Finally, we wish to acknowledge the assistance of Zack Brandt in analyzing the geographic distribution of providers nationally.

\section{Endnotes}

1 "Coordination" of Section 5310 funded activities has been a part of Federal Transit Administration programs since 1987, and has been required government wide since the signature of Executive Order 13330 in 2004. On-the-ground implementation of such collaborative arrangements has not been a central feature in states' Section 5310 networks, however.

${ }^{2}$ One agency was an outlier; reporting more than 1 million one-way trips. Even with this outlier removed, no statistical differences emerged. We did not assess distances of trips or the type of service provided (i.e., door-to-door, curb-to-curb, fixed route, extended hours, etc.).

\section{References}

Arcury, T. A., J. S. Preisser, W. M. Gesler, and J. M. Powers. 2005. Access to transportation and health care utilization in a rural region. The Journal of Rural Health 21 (1): 31-38.

APRIL. 2001. Rural transportation for people with disabilities: Transportation Equity Act of the 21st Century (TEA 21) 2003 re-authorization. Kent, OH: Association of Programs for Rural Independent Living.

Arnold, N., T. Seekins, and R. Nelson. 1997. A comparison of vocational rehabilitation counselors: Urban and rural differences. Rehabilitation Counseling Bulletin $41(1): 2-14$. 
Bernier, B. and T. Seekins. 1999. Rural transportation voucher program for people with disabilities: Three case studies. Journal of Transportation and Statistics 2(1): 61-70.

Burkhardt, J. E., C. A. Nelson, G. Murray, and D. Koffman. 2004. Toolkit for rural community coordinated transportation. Washington, DC: Transportation Research Board (TCRP No. 101).

Community Transportation Association of America. 2006. How we assure senior mobility. Federal Express. Retrieved May 2, 2006, from http://www.ctaa.org/ fednews/fedexpress/senior_mobility.asp.

Community Transportation Association of America. 2001. Status of rural public transportation-2000. Washington, DC: Community Transportation Association of America.

Community Transportation Association of America. 1995. Atlas of public transportation in rural America. Washington, DC: Community Transportation Association of America.

Denson, C. R. 2000. Public sector transportation for people with disabilities: A satisfaction survey. Journal or Rehabilitation 66 (3): 29-37.

Dillman, D. A. 2000. Mail and electronic surveys: The tailored design method, 2nd ed. New York: John Wiley \& Sons.

Federal Transit Administration. 1998. The Elderly and Persons with Disabilities Program guidance and application instructions. [Circular C9070.1E.] Retrieved May 2, 2006 from http://www.fta.dot.gov/legal/guidance/circulars/9000/946_ 1212_ENG_HTML.htm.

Fetterman, D. M. 1998. Ethnography. In L. Bickman and D. J. Rog, eds., Handbook of applied social research methods. Thousand Oaks, CA: Sage Publications, 473-504.

Government Accountability Office. 2003. Transportation-disadvantaged populations: Some coordination efforts among programs providing transportation services, but obstacles persist (GAO-03-697). Washington, DC: Government Accountability Office.

Government Accountability Office. 2004. Transportation-disadvantaged seniors: Efforts to enhance senior mobility could benefit from additional guidance 
and information (GAO-040971. Washington, DC: Government Accounting Office.

Jackson, K.O., T. Seekins, and R. Offner. 1992. Involving consumers and service providers in shaping a rural rehabilitation research agenda. American Rehabilitation 18 (1): 23-29.

Johnson, M., and B. Shaw. 2001. To ride the public buses: The fight that built the movement. Louisville, KY: The Avocado Press.

Kidder, A. 1989. Passenger transportation problems in rural areas. In W. R. Gillis, ed., Profitability and mobility in rural America. University Park, PA: The Pennsylvania State University Press.

National Council on Disability. 2005. The current state of transportation for people with disabilities in the United States. Washington, DC: National Council on Disability.

Nosek, M., Y. Zhu, and C. Howland. 1992. The evolution of independent living programs. Rehabilitation Counseling Bulletin 35 (3): 174-189.

Rucker, G. 1994. Status report on public transportation in rural America. Washington, DC: Community Transportation Association of America.

Sundeen, M., J. B. Reed, and M. Savage. 2005. Coordinated human service transportation: State legislative approaches. Denver, CO: National Conference of States Legislatures.

Tonsing-Gonzales, L. 1989. Rural independent living: Conquering the final frontier. In G. Foss, ed., Meeting the rehabilitation needs of rural America. Missoula, MT: Rural Institute on Disabilities.

U.S. Census Bureau. 2000. Census 200 Summary File 3, Table P42.

U.S. Department of Transportation. 1980. Planning guidelines for coordinated agency transportation. Washington, DC: U.S. Department of Transportation (DOT - 1-87-33).

Zeilinger, C. 2003. The 20-year retrospective. Community Transportation (Fall): 7-9. 


\section{About the Authors}

TOM SEekinS (ruraldoc@ruralinstitute.umt.edu) is a professor of psychology and director of the Research and Training Center on Disability in Rural Communities, University of Montana.

ALeXANDER ENDERS (enders@ruralinstitute.umt.edu) is a senior research associate at the Rural Institute on Disabilities, University of Montana. Ms. Enders has been intensely involved in the disability rights movement for more than 30 years and has particular expertise in independent living. She is known internationally for her work in assistive technology for people with disabilities.

Alison Pepper (iluvsandiego@msn.com) is a graduate student in the Department of Psychology at the University of Montana. Her interests are in the area of health psychology.

STEPHen StICKA (stephen.sticka@gmail.com) was a student in the Department of Psychology with particular interest in political and organization issues. 